\title{
Management of a 15-year-old scaphoid non-union
}

\author{
Kai Yuen Wong, ${ }^{1}$ Olivia Sharp, ${ }^{2}$ Phillip Johnston ${ }^{3}$
}

\begin{abstract}
${ }^{1}$ Department of Plastic Surgery, Cambridge University Hospitals NHS Foundation Trust, Cambridge, UK

${ }^{2}$ Department of Plastic Surgery, Salisbury NHS Foundation Trust, Salisbury, UK

${ }^{3}$ Department of Trauma and Orthopaedic Surgery, Cambridge University Hospitals NHS Foundation Trust, Cambridge, UK
\end{abstract}

\section{Correspondence to} Mr Kai Yuen Wong, kaiyuen.wong@cantab.net

KYW and OS contributed equally.

Accepted 20 December 2017

\section{SUMMARY}

Scaphoid non-union affects wrist joint function and is often associated with a predictable pattern of degenerative change. A 30-year-old man presented with a symptomatic 15 -year-old right scaphoid fracture with secondary scaphoid non-union advanced collapse of his right wrist. There was no evidence of avascular necrosis. The initial injury was from a fall onto his outstretched hand. We performed a right scaphoid open reduction, internal fixation and iliac crest bone graft. One year after the operation, the patient had good wrist function and grip strength. A CT scan showed union of the fracture. Studies have shown that if the time between initial fracture and treatment of non-union exceeds 5 years, the chances of healing of the non-union are markedly reduced. In our case, despite the long duration between timing of injury and surgery, there was union and good return of function.

\section{BACKGROUND}

The scaphoid is the most commonly fractured bone in the carpus and patients are often healthy, young individuals. Fractures disrupt the retrograde, unipolar blood supply to the proximal bony fragment, compromising its potential to heal. Non-union of scaphoid fractures are reported to occur in about $10 \%$ of cases. Scaphoid non-union affects wrist joint function and is often associated

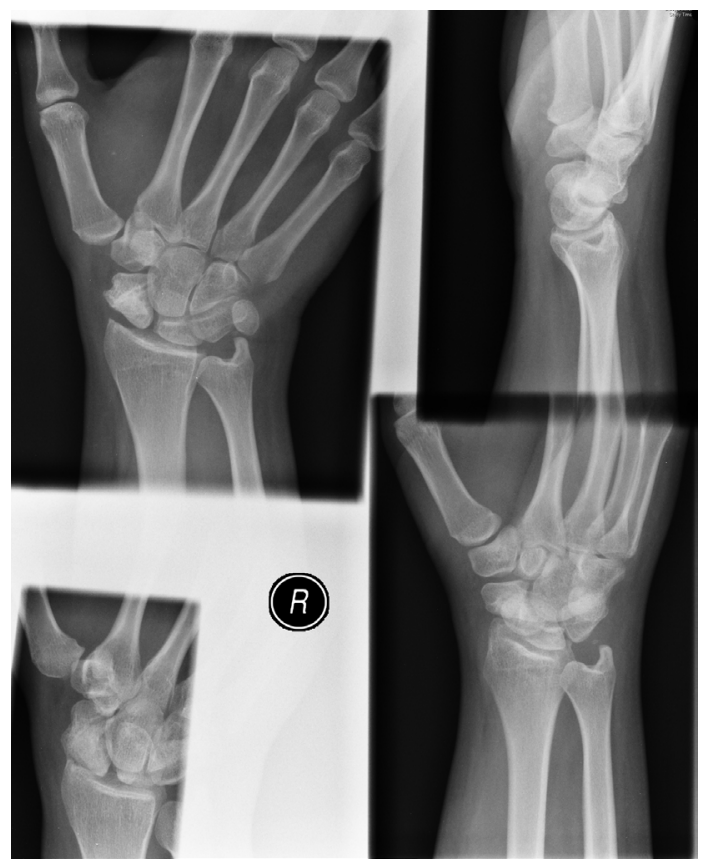

Figure 1 Preoperative scaphoid view radiographs. with a predictable pattern of degenerative change, more specifically scaphoid non-union advanced collapse and arthritis. Management options include bone graft techniques, screws, Kirschner wires and salvage procedures, with choice of treatment dependent on both patient and disease characteristics. Surgery has a reported failure rate of $25 \%-45 \%$. We review the literature and present the management and outcomes of a 15-year-old scaphoid non-union.

\section{CASE PRESENTATION}

A 30-year-old right-hand-dominant man presented with a symptomatic 15 -year-old right scaphoid fracture. The initial injury was from a fall onto his outstretched hand. He was a fit and well non-smoker and was aware of the scaphoid fracture and had elected for conservative management at the time. In the year preceding presentation to our hand unit, the patient had increasing pain and stiffness and found that this was limiting his daily activities. There was no history of additional trauma.

\section{INVESTIGATIONS}

Radiographs demonstrated a fracture through the waist of the scaphoid with significant humpback deformity and a compensatory dorsal intercalated segment instability deformity of the lunate. His carpus was representative of stage I scaphoid non-union advanced collapse, as shown in figure 1. There was no evidence of avascular necrosis on MRI, as shown in figure 2 .

\section{TREATMENT}

We discussed the management options with the patient and the potential need for salvage surgery if primary intervention failed. We performed a right scaphoid open reduction, internal fixation and iliac crest bone graft. Postoperatively he was placed in a plaster cast for 6 weeks and then a Futuro splint for 6 weeks.

\section{OUTCOME AND FOLLOW-UP}

Six months after the procedure, the patient had good wrist function and grip strength, and radiographs demonstrated union of the fracture, shown in figure 3. A CT scan performed 7 months postoperatively further confirmed union of the fracture, as shown in figure 4.

\section{DISCUSSION}

Delayed presentation of scaphoid non-union continues to present significant challenges to hand surgeons. If stable fibrous non-union of the scaphoid 


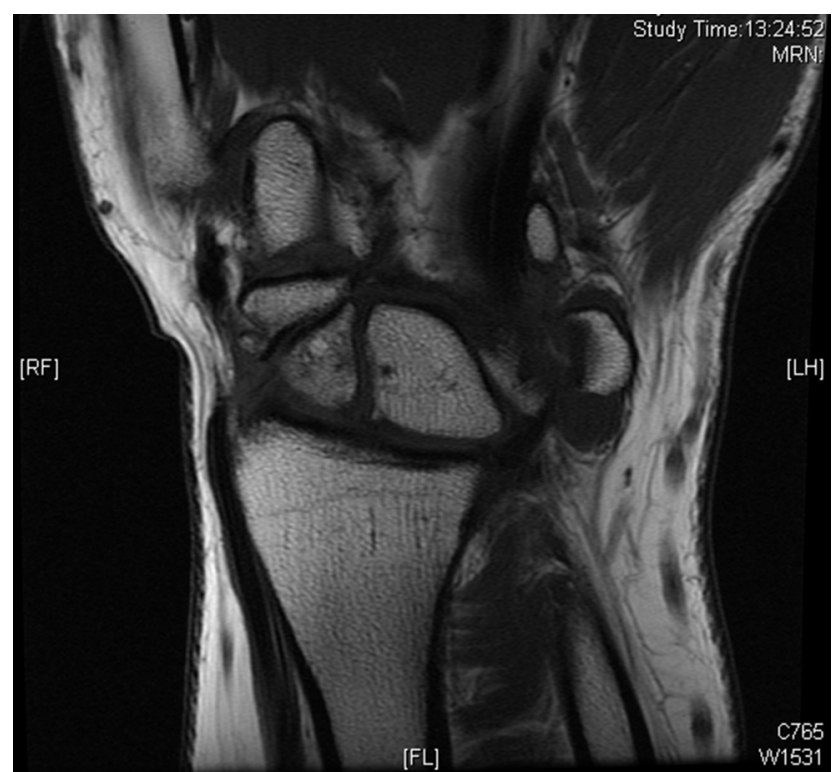

Figure 2 Coronal section of preoperative T1-weighted MRI of the right wrist demonstrating scaphoid non-union.

occurs, compression screw fixation with or without bone grafting has been shown to be a successful treatment option. ${ }^{2-4}$ Management is determined in part by the extent of wrist degeneration, which can be graded using the Mack-Lichtman system. In Mack-Lichtman type I disease, there is no significant arthritis and the first-line surgical management is non-vascularised bone graft with or without internal fixation. Mack-Lichtman type II non-unions are more unstable due to fragment displacement, and therefore bone grafting and an internal screw are required to restore scaphoid alignment and union.

Mack-Lichtman type III non-unions are associated with arthritic features such as joint space narrowing between the radius and scaphoid, and beaked changes of the radial styloid. Surgical options here are as for type II plus radial styloidectomy if the arthritis is limited to the styloid. If there is significant scaphoid fossa arthritis, the scaphoid may not be salvageable and proximal row carpectomy may be needed. Mack-Lichtman type IV or V scaphoid non-unions have midcarpal arthritis, with and without radiolunate involvement, respectively. For these,

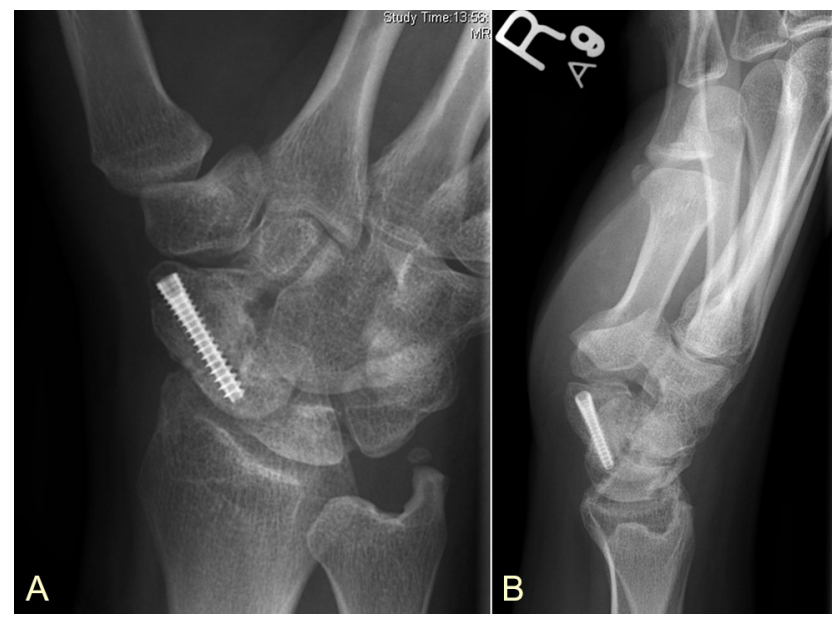

Figure 3 (A) Anteroposterior and (B) lateral radiographs taken 6 months postoperatively illustrating fracture union.

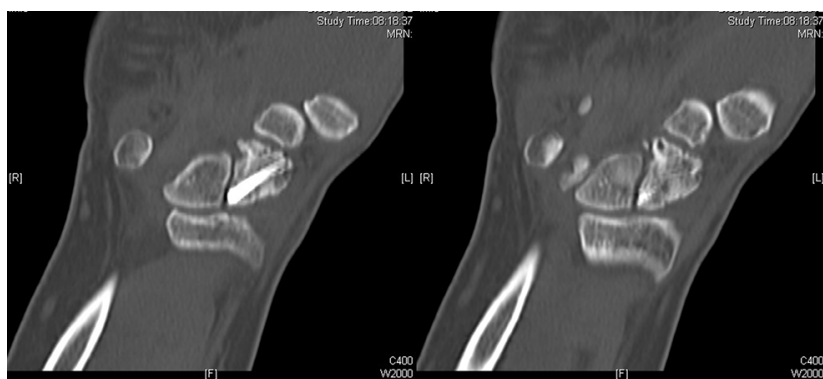

Figure $4 \mathrm{CT}$ image performed 7 months postoperatively further demonstrating fracture healing.

motion-sacrificing operations such as complete wrist fusion may be necessary. ${ }^{6}$

As well as stage of disease, it is recognised that the time interval between the original injury and surgery is a key determinant in achieving successful union. ${ }^{7}$ Inaparthy et $a l^{8}$ concluded that if the time between initial fracture and treatment of non-union exceeds 5 years, the chances of healing of the non-union are markedly reduced.

The longest reported duration of delay to successful primary surgery was by Capo et al, ${ }^{9}$ who described a 28 -year-old scaphoid non-union treated with a non-vascularised bone graft. In this case and our own, despite the long duration since injury, the patients presented with stage I disease with no avascular necrosis or previous failed surgery. Both cases led to fracture union and good return of function.

Kent et $a l^{10}$ published a retrospective cases series looking at 13 patients with scaphoid non-union advanced collapse who were over 2 years post injury with radiographic evidence of degenerative change. All underwent bone grafting and fixation. There was failure to unite in three cases, in which all had either proximal pole fractures, previous failed surgery or stage IV carpal degeneration. Shah and Jones ${ }^{11}$ found that the development of avascular necrosis and failure of previous surgery also lead to poor outcomes after repair for scaphoid non-union. ${ }^{11}$

From the above literature, the negative prognostic indicators emerging are proximal pole fractures, previous failed surgery, advanced stage carpal degeneration and presence of avascular necrosis. In patients with these poor prognostic features, surgical options include either a pedicled or a free vascularised bone graft and screw, or motion-sacrificing operations.

Learning points

- This case demonstrates that scaphoid non-union advanced collapse has a varied timescale of progression, as even after 15 years there was only Mack-Lichtman type I disease.

- Rather than time frame alone, presence of negative prognostic indicators including avascular necrosis, previous failed surgery, proximal pole fractures and stage IV carpal degeneration should guide management.

- The patient needs to be central to, and involved with, the decision process when deciding between motion-sparing and motion-sacrificing treatment options.

- This case of a long-standing scaphoid non-union challenges the belief that if the time interval between injury and surgery exceeds 5 years, the chances of healing of the non-union are markedly reduced. 
In summary, this case further demonstrates that chronic non-union without additional negative prognostic indicators can be treated with bone graft and screw fixation as a primary intervention, despite the long duration to surgical management. Therefore in this specific patient group there is evidence that reconstruction should be considered before salvage procedures such as proximal row carpectomy and wrist fusion.

Contributors KYW and OS contributed equally to this work. All authors, including $\mathrm{PJ}$, contributed significantly to the drafting, review and approval of the manuscript.

Competing interests None declared.

Patient consent Obtained.

Provenance and peer review Not commissioned; externally peer reviewed.

(C) BMJ Publishing Group Ltd (unless otherwise stated in the text of the article) 2018. All rights reserved. No commercial use is permitted unless otherwise expressly granted.

\section{REFERENCES}

1 Huang YC, Liu Y, Chen TH. Long-term results of scaphoid nonunion treated by intercalated bone grafting and Herbert's screw fixation-a study of 49 patients for at least five years. Int Orthop 2009;33:1295-300.
2 Somerson JS, Fletcher DJ, Srinivasan RC, et al. Compression screw fixation without bone grafting for scaphoid fibrous nonunion. Hand 2015;10:450-3.

3 Gaebler C, McQueen M. Carpus fractures and dislocations. In: Bucholz RHJ, Court-Brown CM, Tornetta P III, eds. Rockwood and green's fractures in adults 7 . Philadelphia: Williams and Wilkins, 2010:800.

4 Slade J, Merrell G. Percutaneous treatment of grade I to III scaphoid nonunions. Wiese $\mathrm{S}$, ed. Operative techniques in orthopaedic surgery. Philadelphia: Lippincott, Williams and Wilkins, 2011:2260.

5 Mack G, Kelly J, Lichtman D. Scaphoid non-union. In: Lichtman D, Alexander A, eds. The wrist and its disorders. Philadelphia: Saunders, 1997:234-67.

6 Steinmann SP, Adams JE. Scaphoid fractures and nonunions: diagnosis and treatment. J Orthop Sci 2006;11:424-31.

7 Nakamura R, Horii E, Watanabe K, et al. Scaphoid non-union: factors affecting the functional outcome of open reduction and wedge grafting with Herbert screw fixation. J Hand Surg Br 1993;18:219-24.

8 Inaparthy PK, Nicholl JE. Treatment of delayed/nonunion of scaphoid waist with Synthes cannulated scaphoid screw and bone graft. Hand 2008;3:292-6.

9 Capo JT, Shamian B, Rivero S. Chronic scaphoid nonunion of 28-year duration treated with nonvascularized iliac crest bone graft. J Wrist Surg 2013;2:79-82.

10 Kent ME, Rehmatullah NN, Young L, et al. Scaphoid nonunion in the presence of a degenerate carpus: don't rush to salvage surgery. J Hand Surg Eur Vol 2012;37:56-60.

11 Shah J, Jones WA. Factors affecting the outcome in 50 cases of scaphoid nonunion treated with Herbert screw fixation. J Hand Surg Br 1998;23:680-5.

Copyright 2017 BMJ Publishing Group. All rights reserved. For permission to reuse any of this content visit http://group.bmj.com/group/rights-licensing/permissions.

BMJ Case Report Fellows may re-use this article for personal use and teaching without any further permission.

Become a Fellow of BMJ Case Reports today and you can:

- Submit as many cases as you like

- Enjoy fast sympathetic peer review and rapid publication of accepted articles

- Access all the published articles

- Re-use any of the published material for personal use and teaching without further permission

For information on Institutional Fellowships contact consortiasales@bmjgroup.com

Visit casereports.bmj.com for more articles like this and to become a Fellow 